\title{
O CONTRATO SOCIAL EM SAMUEL PUFENDORF
}

\section{The Samuel Pufendorf's social contract}

\author{
Luiz Felipe Netto de Andrade e Silva Sahd
}

Professor adjunto dos cursos de Graduação e Pós-Graduação em Filosofia da Universidade Federal de Uberlândia (UFU), Uberlândia, MG - Brasil, e-mail: felipesahd@yahoo.com.br

\begin{abstract}
Resumo
O presente artigo tem como objetivo reconstruir argumentos centrais desenvolvidos por Saumuel Pufendorf. Pufendorf opera um compromisso explícito entre Hobbes e a lei natural tradicional. De Hobbes, ele retém a doutrina individualista do contrato social quanto ao direito de governar; mas rejeita categoricamente sua doutrina da soberania, em proveito de um código laico da lei natural que expõe em detalhes em seus livros. Segundo o argumento de Pufendorf, na origem todos os homens viviam num "estado de natureza" em que eram livres, iguais e sem governo. Por conseguinte, todo governo provém de um contrato social, como ensinou Hobbes. Contudo, embora os homens sejam naturalmente apolíticos, eles não são naturalmente egoístas, mas, ao contrário, sociais e sociáveis. Desde então, seu estado natural é um estado social e pacífico, em que podiam aplicar e aplicavam a lei natural tal como a descobriu sua razão.
\end{abstract}

Palavras-chave: Estado de natureza. Lei natural. Contrato social. Soberania. Estado. 


\begin{abstract}
The present article aims at reconstructing Samuel Pufendorf's central arguments. It is an explicit compromise between Hobbes and more traditional natural law. Pufendorf accepts Hobbes's individualistic social contract doctrine regarding the right to rule but emphatically rejects his doctrine of sovereignty in favor of a secular code of natural law, which he sets forth in great detail in his books. According to Pufendorf's argument, all men originally lived in a "state of nature" in which they were free, equal, and without rule; hence, all rule arises from a social contract, as Hobbes had taught. Although men are naturally apolitical, however, they are not naturally selfish but rather social and sociable; therefore, their natural state was a social and peaceful one in which they could and did practice the law of nature as discovered by reason.
\end{abstract}

Keywords: State of nature. Natural law. Social contract. Sovereignty. State.

\title{
Direito natural e sociabilidade
}

Na tradição de Jean Bodin, Hugo Grotius e Thomas Hobbes, Samuel Pufendorf desenhou os contornos do Estado moderno a partir da noção de soberania. O summum imperium é posto na dependência dos dois contratos sociais - da votação da constituição e do ato de submissão - firmados por sujeitos livres e detentores da razão natural. Como os seus contemporâneos, Pufendorf também extrai da filosofia política um arsenal de princípios aplicáveis ao direito natural ao empreender uma investigação criteriosa sobre o impacto das noções de indivíduo e legalidade na solução definitiva do problema da justiça e das relações mútuas dos homens. Movendo-se, assim, na órbita do iuris naturalis scientia, constrói um "sistema" capaz de fundamentar a ética individual e social sem contar com as hipóteses religiosas. ${ }^{1}$ Partindo da filosofia política e dos princípios racionais axiomáticos, evidentes, deduzidos com coerência (more geometrico), Pufendorf faz uma tarefa nada fácil de distinguir e assinalar o lugar próprio do direito natural no pensamento filosófico e jurídico do século XVII. ${ }^{2}$ Se na sua obra mais importante (De jure naturae et gentium) o autor 
1 O impacto desta decisão é enorme e reflete um movimento iniciado pela escolástica espanhola, em particular por Francisco de Vitória. A reformulação da razão natural tornou-se fundamental no direito das gentes da primeira modernidade, quando a colonização promovida pela coroa espanhola precisava ser administrada juridicamente. Foi preciso resolver alguns impasses, vencer preconceitos e tomar duas decisões axiomáticas: os habitantes das terras recémdescobertas deveriam ser definidos como pessoas possuidoras da mesma natureza dos colonizadores europeus, isto é, os selvagens eram seres humanos e pessoas juridicamente responsáveis por seus atos, estavam assim aptos como parceiros legais para contratos e acordos que regulassem as vidas com os novos parceiros do reino hispânico. Se os novos parceiros legais são incorporados como pessoas de direito, então também deveria ser-lhes atribuída uma razão natural. "Por ser o homem um animal rationale, um ser racional, a razão também faz parte da natureza humana, independentemente de sua pecaminosidade” (SCHMIDT-BIGGEMANN, 2003, p. 160). Cada indivíduo dotado de direitos naturais era aceito também como uma pessoa dotada de razão, não importando aqui se era ou não cristã. Essas teses foram aceitas pelos juristas holandeses arminianos, sobretudo por Hugo Grotius (HAGGENMACHER, 1983, p. 489-496; TUCK, 1979, p. 64; TUCK, 1999, p. 78-79; VILLEY, 2005, p. 655). Desse modo, o objeto da teoria do direito natural é um direito moral que é natural em dois sentidos: por estar inscrito na natureza do homem e por ser acessível por meio da razão natural, em vez da revelação divina (HAAKONSSEN, 1996; HOCHSTRASSER, 2000). Um direito moral cujo papel atua como fundamento normativo e padrão universal à política e ao direito positivo (HUNTER, 2001).

2 Apesar das aparências, René Sève insiste que é preciso relativizar a importância do raciocínio more geometrico na doutrina dos jusnaturalistas modernos: "La déduction logique y est toujours mêlée aux arguments d'autorité avances comme preuves ou confirmations, et surtout aux considérations anthropologiques émanant de l’expérience” (SÈVE, 1989, p. 9). A confirmação de lacunas na dedução lógica dos princípios e o seu preenchimento com argumentos de autoridade não invalidam, portanto, o projeto moderno de uma moral com “fundamentos inabaláveis". É isso justamente o que pensou ter realizado Pufendorf no clássico De jure naturae et gentium (publicado em 1672). Para ele, a obra preenche inteiramente este projeto, expõe "o sistema do direito natural [...] que somente a boa moral e a boa política contém [disciplina juris naturae [...] quae genuinam ac solidam doctrinam moralem \& civilem absolvit]", e corresponde à ideia de uma "verdadeira ciência [verae scientiae]” (PUFENDORF, 1998a, I, II, §4). Desse modo, a moral “[...] baseia-se em fundamentos inabaláveis, dos quais podem-se tirar verdadeiras demonstrações, capazes de produzir uma ciência sólida” [“[...] omnino ejusmodi fundamentis nititur, ut exide genuinae demonstrationes, quae solidam scientiam parere sint aptae, deduci queant”] (PUFENDORF, 1998a, I, II, §4). É correta a avaliação de Simone Goyard-Fabre: “A obra de Pufendorf é, do ponto de vista metodológico, mais complexa e mais sutil: de fato, mesmo o jurisconsulto declare, também ele, ter a intenção de construir um 'sistema do direito natural', ele se afasta do esquema hipotético-dedutivo dos matemáticos e, no curso de seus escritos, a razão adquire um perfil diferente, de modo que, quando Thomasius lembra a admiração que Pufendorf dedicava a seu mestre Weigel e aproxima a evolução de seu pensamento àquela adotada por Grócio e Hobbes, ele suprime o que faz a originalidade de textos nos quais as constâncias se manifestam entre as nuances” (GOYARD-FABRE, 2007, p. 40). 
oferece uma definição precisa, é no manual intitulado De Officio Hominis et Civis Juxta Legem Naturalem Libri Duo que encontramos a melhor abordagem da diferença deste campo do saber outrora identificado com outros ramos do conhecimento. A obra escrita para facilitar a compreensão dos alunos e professores que iniciam a árdua tarefa da pesquisa jurídico-filosófica do direito trata de mostrar que o estudo e a prática do direito natural se diferenciam tanto do direito civil como da teologia moral. O conteúdo do direito natural, suas fontes, seu método, seu espírito dependem em grande medida das fronteiras atribuídas a essa ciência. A diferença não é só de conteúdo e temas específicos, mas também pela forma podemos identificar a especificidade do assunto cujo vocabulário empregado para explicar o direito natural e o princípio de que parte, a sociabilidade, são próprios. Para Pufendorf, o conteúdo e os temas do direito natural se organizam sobre seis pontos básicos: primeiro, o direito natural tem a pretensão de consolidar os princípios universais que fundamentam os deveres comuns de todos os homens em todos os tempos e lugares. É o direito que determina as obrigações no Estado concreto, atribuindo à teologia moral o papel restrito de efetivá-las única e exclusivamente nas diferentes ordens confessionais segundo as crenças e credos dos fiéis. Segundo, as leis naturais são demonstradas, conhecidas e compreendidas mediante a razão natural do homem. Este não precisa de outro auxílio além de suas faculdades racionais. Terceiro, o direito natural é descoberto, metodologicamente, mediante a razão humana, não é necessário apelar para uma instância sobrenatural ou buscar ajuda além das suas próprias forças. Quarto, a finalidade que anima o direito natural é justamente a de conduzir, educar e proporcionar ao homem a condição para se transformar num membro útil à sociedade em que vive, proporcionando os instrumentos das mudanças e realizações dos fins que ele próprio e a sociedade se propõem. Quinto, o direito natural serve para julgar a maior parte das ações externas dos homens, pois o que pertencem ao foro interno, à consciência, não se pode emitir qualquer juízo segundo os seus critérios. Sexto, o direito natural considera a natureza corrompida do homem, uma vez sem o reconhecimento dessa limitação seria difícil admitir a possibilidade do homem viver em sociedade e em paz com seus semelhantes.

O princípio mais importante do direito natural é que todo homem tem o dever de cultivar e preservar a sociabilidade (PUFENDORF, 1998a, II, III, §20); ${ }^{3}$ esta obrigação implica a existência dos deveres numa tripla

3 Aqui, Pufendorf decompõe a natureza humana em três elementos básicos para determinar a lei de seu ser. Estes componentes sintetizados na socialitas são: o amor sui (o amor de si ou o impulso de autoconservação), a imbecillitas e a naturalis indigentia, e a pravitas animi, que incita o homem a prejudicar o seu semelhante. 
dimensão: diante de Deus, diante de si mesmo e diante dos outros (PUFENDORF, 1997, I, IV e I, V). Mais ainda, enquanto indivíduo, todo homem deve observar que as suas ações produzem efeitos em outras pessoas, e mediante essa tríade de obrigações ele deve atuar de modo a se chegar à condição de elemento útil à sociedade.

O primeiro dever de quem vive coletivamente está na busca incansável de todos os meios possíveis para não causar dano a nenhum outro (tese defendida também por Grotius e Hobbes); mas ficar aí somente não basta, a busca incansável seria insuficiente. O homem também precisa eliminar os meios e as ocasiões propícias a provocar uma reação antissocial, isto é, devem atuar visando aos outros, respeitando a dignidade e a igualdade de cada um, e evitar qualquer tipo de injúria e dano aos demais: "que cada um estime e trate o outro como naturalmente igual a ele ou como igualmente homem" (PUFENDORF, 1997, I, VII, §1). Desta afirmação, porém, Pufendorf deduz o segundo dever: a sociedade - já não considerada comunidade - deve se fundamentar no reconhecimento mútuo da igual dignidade de todos os homens, algo oposto ao domínio de uns sobre os outros como ocorria em épocas passadas. Para manter a sociedade unida e os seus membros vivendo em harmonia é preciso conseguir que o dever de benevolência - o terceiro dever - prevaleça sobre os outros (PUFENDORF, 1997, I, VIII).

O respeito, a igual dignidade e a benevolência são três deveres que servem para justificar as obrigações nas ações políticas e nos atos jurídicos praticados pelos indivíduos na sociedade. Orientam as relações intersubjetivas que se utilizam da linguagem, como contratos, pactos, promessas, compras e vendas de propriedades, doações, heranças, etc. Mas também deles derivam as obrigações próprias do indivíduo como membro de uma família e de um Estado.

Neste ponto, Pufendorf parece incorporar as teses de Sêneca, quando o filósofo latino afirma que as paixões mais odiosas e detestáveis são a injustiça e a ingratidão, ambas levam irremediavelmente à dissolução da sociedade e à loucura de seus habitantes (PUFENDORF, 1997, I, VIII, §8). Desse modo, para Pufendorf, a sociabilidade se converte no fundamento do direito natural, também na justificação da existência e do desenvolvimento da sociedade humana. O homem dentro da coletividade cumpre certas obrigações, podendo alcançar a condição de membro útil para todos e afastar uma vez por todas as ações injustas e ingratas (PUFENDORF, 1997, I, V; II, V, §4; II, XIII, $\S 2$ e II, XVII, §4). Mais do que preservar a segurança e garantir a boa vida em sociedade, o homem cumpridor de seus deveres promove o desenvolvimento social, econômico, político e cultural. 
Em outras palavras, o autor afirma no De jure naturae et gentium que a natureza humana exige dos indivíduos a convivência pacífica com outros indivíduos da mesma espécie ao manter e incrementar a sociabilidade de todos. A observação da natureza mostra que o homem é um ser talhado para viver em sociedade, pois a sua constituição física indica claramente que ele foi feito para viver com os outros numa relação societária. Por um lado, ele tem numerosas necessidades naturais, por outro, a natureza não o dotou diretamente dos meios indispensáveis para satisfazer a essas necessidades. Ao contrário de alguns animais que, sem sacrificar suas necessidades naturais, podem viver sozinhos, fora do estado social, o homem só pode suprir suas necessidades de modo satisfatório associando-se a outros homens. O estado de sociedade é uma necessidade lógica decorrente do fato de que as necessidades naturais do homem superam as possibilidades das quais dispõe para satisfazê-las sozinho (SCHINO, 1995, p. 25-32). O fim almejado pelos seres humanos consiste em tornar efetiva a existência natural e irrenunciável do modo de ser do homem de viver em sociedade pacificamente: "Com estas premissas, escreve Pufendorf, parece que a lei natural fundamental é a seguinte: cada homem deve cultivar e manter na medida do possível a sociabilidade" (PUFENDORF, 1998a, II, III, §15). Embora a finalidade do homem seja realizar o atributo por excelência da condição humana, a socialitas, os indivíduos que vemos diante de nós são inconstantes e egoístas (homens pecadores), mais preocupados com os próprios interesses e movidos por paixões muito pouco dignificantes. Como dar conta deste intervalo entre a natureza do homem tal como ela realmente é e a natureza tal como deveria ser? Se Pierre Laurent tem razão ao defender a tese de um "antropocentrismo moderado" na doutrina de Pufendorf, pode-se falar então que a sociabilidade, no seu sentido mais profundo, vincula estreitamente "o ser individual do homem ao seu ser em relação” (LAURENT, 1982, p. 109). Por princípio, Pufendorf recusaria um tratamento da condição humana a partir da sua individualidade absoluta, ela teria somente um valor relativo na medida em que dependeria da sociedade (OLIVEIRA, 1996, p. 112-113).

O homem solitário não é um indivíduo autônomo, mas sim um sujeito vulnerável (DENZER, 1972, p. 92-93). As necessidades de companhia, sobrevivência e viver melhor impulsionam o homem a associar-se para construir mutuamente uma sociedade onde todos coloquem em comum seus escassos saberes, habilidades e muitas necessidades. Produto da associação aleatória e coincidência temporal de interesses renovados pelas preferências individuais, a sociedade converte-se em realidade a partir da admissão de 
todos da necessidade absoluta por uma vida gregária. Portanto, a natureza do homem e de sua interação comunitária conduz necessariamente ao estabelecimento do Estado: "É tamanha a estupidez da maioria dos homens e a violência das suas paixões, que apenas bem poucos conferem a estas questões a consideração que lhes é devida. Portanto, não restou nenhum remédio mais eficaz para conter a maldade dos homens que o fornecido pelos Estados” (PUFENDORF, 1998b, VII, I, §11).

Estamos diante da concepção da sociedade composta por elementos justapostos que têm carências de toda ordem e espécie. Ela não é a comunidade do ideal político aristotélico, mas a conjunção harmonizada de elementos diferentes num mesmo espaço e durante um tempo determinado. Mais ainda, a sociedade não é o produto do instinto sociável, psicológico, construído a partir da ordem física (appetitus societatis). Ela é um dever. Separada de modo radical dos "seres físicos”, a doutrina dos "seres morais" (entia moralia) parece contradizer o naturalismo de Hobbes e de Spinoza e se vincular às fórmulas incertas de Grotius (GROTIUS, 1919, Prolegômenos, §§7-8). Mas enquanto neste último o appetitus societatis é um impulso da natureza humana e a vida social flui como sua consequência natural, em Pufendorf a exigência da imbecillitas faz aflorar uma socialitas que permite deduzir o conteúdo mais profundo da vida associativa. Onde em Grotius se manifestava uma tendência inata do homem a viver em sociedade, em Pufendorf se distingue o objetivo regulador (WOLF, 1927, p. 89-90). Em suma, a "antropologia bifronte" de Pufendorf pretende a "harmonização sintética" de dois relevantes perfis da natureza humana. ${ }^{4}$ No máximo, o jurisconsulto admite um appetitus societatis restrito às comunidades pequenas, como a amizade, o matrimônio e a família, mas não ao Estado (PUFENDORF, 1998b, VII, I, §3). A relação entre a socialitas e o appetitus socialis se configuraria desse modo: a sociabilidade seria a categoria objetiva do valor do agir ético-social, isto é, constituiria o conteúdo da lei natural. As causas vitais ou psicológicas (causae impulsivae) da atuação da lei natural seriam as convicções de seu valor e o temor diante de Deus; para as comunidades pequenas, o appetitus societatis, para o Estado, o temor dos outros homens (WELZEL, 1993, p. 74).

4 Segundo BRUFAU, Prats. (1968, p. 56). “Nos encontramos diante de uma antropologia que bebe em duas fontes diversas, mas que deseja desembocar numa harmonização sintética, fazendo da ‘socialitas’ e da 'imbecillitas’ dimensões ontologicamente radicadas na natureza do homem”. 
Admitindo-se que há vários componentes de uma antropologia pessimista na filosofia moral de Pufendorf, ${ }^{5}$ pode-se dizer que o autor demonstraria nitidamente a dificuldade do homem em alcançar por si mesmo a realização das obrigações recorrendo unicamente aos seus possíveis benefícios - pôr em movimento por vontade própria uma busca de padrões morais razoáveis mediante as suas vantagens. Desse modo, o sistema ou a teoria da sociabilidade, fundamento da construção teórica de Pufendorf, exige um desenvolvimento e justificação posterior, que se oferecem nos livros segundo do De officio e sétimo do De jure. Neles, o autor explica os meios mais eficazes para suprimir as más ações, as tendências desviantes e egoístas, os maus usos e costumes, e tudo o que pode prejudicar ao outro e à sociedade. Estes meios, aliás, já estão presentes

5 Não há, aqui, consenso entre os estudiosos de Pufendorf. Alguns comentadores importantes ressaltam a influência desempenhada pela antropologia negativa de Hobbes na teoria de Pufendorf. A razão principal a favor da recepção hobbesiana pode ser descrita desta forma: "no estado de natureza, os indivíduos estão originariamente centrados sobre a singularidade, e não relacionados com outra coisa. Se eles entram em alguma forma de sociedade, isso não se deve a um impulso natural irresistível nem à busca da virtude, mas a um cálculo que visa à utilidade individual. Na medida em que a sociabilidade do homem é finalizada à conservação de si, ele é, paradoxalmente, profundamente egoísta. A mesma definição da lei de natureza, lugar fundamentalmente de todo o direito natural, mostra explicitamente que a necessidade de sociedade é uma consequência da necessidade de conservação e que, portanto, o verdadeiro princípio do direito natural é a autoconservação do indivíduo” (SCATTOLA, 2005, p. 104). Duas teses importantes podem ser retiradas do comentário de Scattola: 1) embora Pufendorf atribua à sociabilidade humana uma função central (primeira lei de natureza), o seu papel não implica absolutamente que os homens sejam sociais e o corpo político seja "coessencial” ao homem, o que poderia sugerir a existência de indivíduos fora da sociedade. Para o comentador, "o princípio de sociabilidade tem, com efeito, um valor exclusivamente epistemológico: é o fundamento lógico que permite a dedução do conjunto jusnaturalista” (SCATTOLA, 2005, p. 105). Desse modo, a sociabilidade não é uma característica intrínseca dos homens, mas uma "ficção lógica” compartilhada por todos que faz das normas do direito natural um produto da razão e uma conquista a partir das determinações fundamentais da natureza humana. 2) sugere a presença de um traço paradoxal na doutrina de Pufendorf, qual seja, "a sociedade humana nasce da sociabilidade natural do homem, mas é fundada recorrendo a um segundo princípio, a imbecillitas, ou seja, a insegurança do direito e, em última instância, o interesse individual” (SCATTOLA, 2005, p. 105). O vínculo de parentesco é insuficiente e restrito às relações afetivas dos pequenos grupos domésticos, e as pessoas fora deste círculo limitado são consideradas pouco confiáveis e inimigas declaradas. Os homens no estado de natureza, portanto, não se ajudam mutuamente e são presas fáceis do "desejo de se prejudicarem": impera entre eles a suspeita perpétua, a desconfiança mútua e o desejo de prepotência "de forma que só é verdadeiramente feliz quem vê no amigo um inimigo em potencial" " "em tempo de paz pensa na guerra”. Cf. também BRUFAU PRATS, 1968, p. 56; PALLADINI, 1990. 
e reconhecidos no estado de natureza, e se efetivam quando os homens decidem construir a cidade e o Estado, isto é, quando decidem viver e realizar a sociabilidade (PUFENDORF, 1997, II, V, §9). Em outras palavras, Pufendorf inicia com grande esforço uma abordagem teórica objetivando justificar a existência das sociedades e a inclusão do homem nelas. Esforço que lhe dá a condição de pensar os problemas do jusnaturalismo sob a ótica da filosofia política e da formação do Estado moderno.

\section{Contrato social e summum imperium}

Quando Pufendorf escreveu e publicou seus textos sobre este tópico, as teses da existência de um estado natural, o regresso à natureza como lugar apropriado e feliz do homem, o sonho de uma idade de ouro, encontrava-se submetida a uma crítica profunda e sob os efeitos de absoluto descrédito. Os jurisconsultos da primeira fase da Ilustração consideravam essa atração pelo retorno à natureza uma curiosa retomada das teorias antigas e uma construção ideal inviável, na melhor das hipóteses, apenas um tema a mais do elenco de questões de um tratado de direito natural. Por isso, ao colocar o problema do estado de natureza como condição necessária, prévia e real para estabelecer os Estados e construir um processo histórico diferenciado, não mais apenas como uma qualidade natural do modo de ser do homem, Pufendorf tenha atraído tantos adversários e contundentes críticas (PALLADINI, 1978, p. 163-271). Não é minha intenção aqui retomar este rico debate, mas apenas salientar as dificuldades da passagem do estado de natureza para a formação do corpo político e, talvez o mais importante, se a doutrina do Estado do autor saxão é uma ampla defesa do modelo absolutista de governo. A preocupação se justifica se consideramos as análises cuidadosas de Michel Villey sobre a formação da mentalidade alemã pelo culto da autoridade e pela apologia da obediência de origem luterana: "Ainda assim, Lutero plantou na alma alemã o germe de um tipo original de positivismo jurídico, fundado na fé religiosa, extremo em suas consequências e que se resume ao culto da autoridade e à apologia da obediência e da disciplina. Esse germe frutificará lentamente na filosofia alemã e também no pensamento comum: não só em um Pufendorf, um Kant ou um Stahl, mas também em um Bismarck. E, conhecendo-se a glória da universidade alemã a partir do século XIX, é possível que por mil canais indiretos nós mesmos sintamos sua influência” (VILLEY, 2005, p. 333). Deixando de lado os exageros do aristotélico Villey, estaria o pensamento de Pufendorf preso às armadilhas da soberania absoluta que permitiu a consolidação definitiva do Estado moderno? Estado que se coloca 
como a única alternativa viável de organização social e sua consequente administração dos conflitos inerentes às relações comunitárias e interações econômicas? Nesse caso, a maioria das pessoas parece pensar que alguma forma de governo centralizado e coercitivo é necessária à ordem social, especialmente nas condições do mundo moderno. Ordem social contrastada às desordens que ocorrem quando faltam regularidade e previsibilidade à vida social e quando há pouca cooperação entre os indivíduos. Muitos acreditam que a segurança básica de pessoas e posses exige a presença do Estado, e a proteção contra os vizinhos e contra os predadores mais distantes, como também da maioria dos bens humanos, seria uma condição da ordem social. Pufendorf, então, responderia integralmente esta exigência da presença forte do Estado como único órgão capaz de oferecer proteção interna e externa ao indivíduo e suas posses.

Eis a definição de Pufendorf: "O Estado é uma pessoa composta, cuja vontade, formada a partir dos pactos de vários indivíduos, é considerada a vontade de todos, e deve valer-se da força e das capacidades deles para realizar a paz e a segurança comum” (PUFENDORF, 1998b, VII, II, §13). ${ }^{6}$

6 Para Pufendorf, é uma opinião sediciosa a de que "o conhecimento do bem e do mal (dum cognitionem boni \& mali)" e do que é vantajoso para o Estado "pertence aos indivíduos (privatos autem homines)". Não diz respeito aos súditos julgar a "argúcia dos meios cuja execução um príncipe ordena para assegurar o bem público (ad se trahunt, cupere esse sicut reges; id quod salva civitate fieri nequit)" (PUFENDORF, 1998b, VIII, I, §5). Isto significa que, se um indivíduo considera uma regra do direito positivo contrária ao direito natural, não é a sua opinião particular que deve prevalecer, mas a deliberação da autoridade competente do Estado que predomina. E a razão é simples: "Como se observa entre os homens a maior diversidade de julgamentos e desejos, pelos quais pode surgir um número infinito de disputas, os interesses da paz também exigem que seja publicamente definido o que cada homem considera seu e o que considera do outro, o que deve ser considerado legítimo, o que deve ser considerado ilegítimo no Estado, o que é honroso, o que é desonroso. Assim como também o que o homem ainda conserva de sua liberdade natural, ou, em outras palavras, como todos deveriam moderar o uso do seu direito, para a tranquilidade do Estado. E, finalmente, o que cada cidadão pode, por direito seu, exigir de outro e de que maneira” ["Praeterea quia máxima inter homines diversitas judiciorum \& adpetituum deprehenditur, ex qua infinita contraversiarum sages oriri potest; inde pacis quoque interest publice definiri, quid cuique suum, quid alienum censeri debeat, quid in civitate pro licito, quid pro illicito, quid pro honesto aut inhonesto habendum. Item, quid cuique ex libertate naturali supersit, aut quomodo cuique jurium suorum usus ad tranquillitatem civitatis sit temperandus"] (PUFENDORF, 1998b, VII, IV, §2). É possível ver aqui a forte influência de Hobbes, por um lado, e o passo mais ousado dado por Locke a respeito do direito de resistência, por outro. Este último, de fato, vai mais longe ao defender que a resistência é justificável se o uso da força pelo governo não só for injusto mas também ilegítimo, isto é, contrário não apenas às leis de natureza mas também às leis positivas (LOCKE, 1988, XVIII, §§203-204). 
O Estado é constituído para superar a situação de guerra em que se degenerou o estado de natureza e oferecer segurança aos homens (BEHME, 1995, p. 112-182). É preciso construir a proteção entre eles e para eles: "Portanto, a causa genuína e principal que levaram alguns pais de famílias perdidos em sua liberdade natural a constituírem os Estados, foi para se protegerem dos males provenientes do homem que ameaçavam o homem" (PUFENDORF, 1998b, VII, II, §1). Como Pufendorf se espelha na violência e brutalidade em que a Europa submergiu durante a Guerra dos Trinta Anos, a insegurança provocada por este sangrento conflito determinou no autor a necessidade imperiosa da formação dos Estados para se alcançar a segurança política, social e econômica dos países territorialmente em expansão. ${ }^{7}$ Estados que pudessem assim garantir o desenvolvimento dos homens. É nos Estados que "se encontra um remédio imediato, bem ajustado às características dos homens" (PUFENDORF, 1997, II, V, §9).

Para fazer parte da sociedade como membro ativo, no entanto, não basta pertencer à espécie humana, é preciso que certas qualidades se manifestem como, por exemplo, servir e subordinar todos os bens (vida, riqueza material e fortuna) no desenvolvimento do Estado. É preciso atuar de acordo com os deveres impostos pelo modelo de cidadão e observar três tipos de regras gerais (os deveres para com o próximo): não provocar injúria, dano e lesão grave aos direitos e propriedades dos outros (é o direito natural à integridade corporal); buscar o bem-estar dos outros e reconhecer mutuamente a igual dignidade de todos os homens (é a igualdade de direitos do cidadão, princípio de justiça da modernidade) (PUFENDORF, 1998a, III, II, §§3-9); ${ }^{8}$ e prevenir as ações destrutivas e os comportamentos negativos, estimulando e fomentando a confiança, a fidelidade e a gratidão ao maximizar a benevolência (PUFENDORF, 1998a, III, III, §§1-17). ${ }^{9}$ Este esquema serve para explicar e justificar as obrigações derivadas dos atos jurídicos, dos usos e costumes, das relações sociais e até mesmo dos atos de fala (PUFENDORF, 1998a, III, VII, §§1-2).

\footnotetext{
Pufendorf também foi um historiador da formação dos Estados modernos, por isso a sua preocupação com os fatos marcantes de sua época (DUFOUR, 1987, p. 103-125; DUFOUR, 1996, p. 107-138; HAAS, 2006).

8 A consequência desse dever é que a igualdade perante a lei é aceita como direito humano.

9 A violência na autodefesa se justifica, no entanto, se o dever pessoal ou político da paz é lesado e é impossível uma solução não-violenta do conflito (PUFENDORF, 1998a, II, V, §1).
} 
Desse modo, Pufendorf defende o Estado moderno como a realização perfeita do desenvolvimento moral da humanidade, o lugar certo da superação do afastamento entre a sociedade civil artificial - construída pelos homens segundo suas necessidades e interesses - e a necessidade moral. O Estado deve ser entendido como criado para nossos fins, nossa proteção e defesa. Pode-se dizer que a adequação dessa forma de organização, como também de suas correspondentes formas de socialização, é determinada pelo seu sucesso em satisfazer nossos fins. Mas também enobrece a união dos homens e de seus esforços em instaurar e efetivar o direito natural. Sua origem está em Deus (PUFENDORF, 1998a, II, III, §20; e ZURBUCHEN, 1991, p. 23-24) e sua finalidade em governar a humanidade (CARR; SEIDLER, 1994, p. 356). O Estado no sistema de Pufendorf é o ponto final da sociabilidade, sua realização plena, e como tal exige um direito que regule e ordene o comportamento dos cidadãos (PUFENDORF, 1998b, VII, III, §2).

Até o momento tratamos apenas da sociabilidade e dos deveres do indivíduo, é preciso portanto estabelecer as condições de possibilidade que o torna membro da sociedade. Que motivações são necessárias para formar a sociedade civil e construir o Estado ordenado?

Uma sociedade que se caracterizaria pela diferença proposta por Johannes Althusius entre multidão e povo (GOYARD-FABRE, 1994, p. 169), ${ }^{10}$ que não se reduziria apenas à simples somatória de indivíduos, esta não passaria da agregação de pessoas sem vínculos permanentes, mas seria pensada como uma associação. Que condições são necessárias para realizar a submissão plena dos associados ao imperium do Soberano? Que realizasse, em suma, a transformação definitiva do Estado de persona ficta em pessoa moral? Mais exatamente, o movimento que vai da massa informe à associação organizada e estruturada sob vínculos permanentes, configura o Estado, estabelece o regime

\footnotetext{
10 Althusius inicia a sua Política deste modo: “A política é a arte de reunir os homens para estabelecer vida comum, cultivá-la e conservá-la. Por isso, é chamada de 'simbiótica'. O tema da política é, portanto, a associação, na qual os simbióticos, por intermédio de pacto explícito ou tácito, se obrigam entre si à comunicação mútua daquilo que é necessário e útil para o exercício harmônico da vida social" ["Politica est ars homines ad vitam socialem inter se constituendam, colendam \& conservandam consociandi. Unde symbiotici vocatur. Proposita igitur Politicae est consociatio, qua pacto expresso, vel tacito, symbiotici inter se invicem ad communicationem mutuam eorum, quae ad vitae socialis usum \& consortium sunt utilia \& necessária, se obligant”] (ALTHUSIUS, 1932, p. 15).
} 
político e o governo, reconhece a autoridade soberana superior e ordena as relações entre os súditos e o governante. Um movimento longo, difícil, repleto de obstáculos, que exige uma solução rápida e a participação do maior número de vontades particulares. É preciso dois tipos de acordos e um decreto (duo pacta et unum decretum). ${ }^{11}$ Nas palavras do autor: "Para que uma multidão se torne uma única pessoa [...], é preciso que seus membros em conjunto tenham de comum acordo unido suas vontades e suas forças por meio de alguma convenção" (PUFENDORF, 1998b, VII, II, §6).

De fato, todo contrato ou convenção, não importa as suas cláusulas, é um compromisso mútuo de indivíduos racionais (livres e iguais), e deve comportar uma promessa recíproca. O contrato social não pode ser exceção à regra, os contratualistas sobretudo neste ponto estão de pleno acordo. Mas quando se trata de precisar quem são os personagens que estabelecem o compromisso mútuo e se obrigam coletivamente, os autores se dividem. É possível admitir primeiro - é a concepção de Hobbes - que a sociedade civil é formada mediante um suposto pacto concluído por indivíduos que consentem em se tornarem seus membros. Cada indivíduo se submete voluntariamente (livremente) à autoridade de um único homem ou de uma assembleia, ao criar uma "república" (Commonwealth), sob a condição de que todos os outros façam o mesmo. Os indivíduos escolhem abrir mão de seu desejo, renunciar à sua liberdade para entregá-la a uma autoridade de um soberano (sovereign) ou de um corpo político (political body), que, doravante, terá todo o poder para fazer reinar a paz e a segurança. Os signatários da convenção (covenant) serão, assim, ligados uns aos outros, uns pelos outros. Não terão mais o direito de exigir algo além dos benefícios que se podem esperar da tranquilidade pública. Nessa concepção do contrato (contract), o soberano recebe o seu poder através do pacto que os indivíduos concluíram entre si. O soberano, porém, não participa do compromisso dos súditos, não faz parte da permuta verbal de direitos e obrigações e nada

11 A passagem para o Estado é uma aliança (foedus) e não um contrato privado, nem a decisão de um só indivíduo. 
promete em troca de sua constituição. ${ }^{12}$ Ele dispõe também do poder absoluto sobre todos os membros do Estado. Em outras palavras, o soberano não está sujeito à convenção, pois ele é o produto desta, e não um dos que a assinou - pois ele é um corpo artificial, totalmente separado da comunidade política, e não um corpo natural. Mesmo que assuma, formalmente, a figura de um indivíduo ou de uma assembleia, que se resuma a uma pessoa física (monarquia) ou se divida em várias (oligarquia), o soberano goza de um poder político absoluto. Tudo o que fizer será legítimo, desde que a convenção seja respeitada; desde que não ameace a vida dos que a assinaram. O pacto como concebe Hobbes é essencialmente um pacto de associação: o fim último é a união de todos em um corpo indivisível, e a submissão inerente às cláusulas da aliança é o meio mais eficaz de realizar a unidade do corpo político (HOBBES, 1996, p. 91-100).

12 Embora nos últimos anos um bom número de comentadores tenha minimizado os efeitos dessa alienação de direitos dos indivíduos temerosos com a própria sorte no estado de guerra generalizado, Norberto Bobbio parece ter alguma razão quando ressalta o papel da obediência cega e absoluta dos súditos. Mesmo não defendendo o regime monárquico absolutista em vigor, o filósofo de Malmesbury é mais rigoroso e severo nas punições às infrações de crimes de lesa-majestade, principalmente nos tipificados pela traição ao soberano. Bobbio escreve: "Em suma, a política de Hobbes, que começara com a tese da unidade do poder, chega - através do fio condutor de um raciocínio excepcionalmente vigoroso - a tecer a trama de uma das teorias da obediência mais radicais jamais conhecida pela história das doutrinas políticas; diante dela, a própria doutrina do direito divino do rei, que era empregada em sua época para defender o absolutismo - ou seja, precisamente o Estado fundado na obediência -, podia ser julgada como uma doutrina moderada. Com efeito, esta última doutrina admitia, pelo menos, a obediência passiva, ou seja, reconhecia a possibilidade de desobedecer à lei civil quando esta contrariasse a lei divina, contanto que essa desobediência fosse, por assim dizer, compensada pela aceitação voluntária da pena que se seguiria à transgressão. Hobbes não admite a obediência passiva; ao contrário, condena-a severamente como um erro. O lógico consequente não deixa aberto aos súditos mais do que um caminho, o da obediência ativa, da obediência em qualquer caso, salvo quando é a própria vida do súdito que está ameaçada” (BOBBIO, 1991, p. 80-81). Por outro lado, o poder soberano é um poder fraco se não for a representação do povo como corpo político: é nessa representação que encontra suas bases e é dela que retira sua força. Simone Goyard-Fabre, analisando o surpreendente capítulo XVI do Leviatã, defende que o estatismo hobbesiano enraíza-se numa "democracia originária": "a unicidade do mandato representativo explica ao mesmo tempo a instituição e o exercício do poder” (GOYARDFABRE, 2003, p. 130). Tese semelhante já era defendida por Richard Tuck: "The liberal interpretation of Hobbes begins from his theory of sovereign as the representative of the citizens. [...] Moreover, in the Elements of Law and De Cive, Hobbes had gone to some lengths to depict the original sovereign created by the inhabitants of the state of nature as necessarily a democratic assembly, which could only transfer the rights of sovereignty to a single person or small group by a majority vote of its members: so Hobbes's theory was in its origins heavily involved with the forms of electoral politics” (TUCK, 1996, p. 35). 
Mas pode-se conceber o pacto social de outro modo, segundo uma fórmula contratual mais complexa que envolve três momentos distintos de elaboração. Os dois momentos principais dessa operação são: o pactum societatis (pacto de associação) em que os homens se reúnem para constituir uma sociedade civil, e o pactum subjectionis (pacto de submissão) em que os membros dessa nova comunidade designam os titulares do poder que terá o encargo de protegêlos, de fazer reinar a paz, governando-os. Na primeira convenção é criada uma associação sem governo cuja união entre iguais é desprovida de relações de sujeição. Na segunda convenção é instituído o governo e os poderes de coação, é "introduzido na associação o fator da soberania e sujeição que lhe faltava anteriormente" (SPITZ, 1987, p. 85). Pufendorf opta por esta última alternativa.

Ao elaborar a sua doutrina do Estado, Pufendorf defende de modo peremptório a teoria do duplo contrato e empreende de forma inconteste a justificativa teórica da necessidade do pacto de submissão ${ }^{13}$. Contra os

${ }_{13}$ Neste ponto em particular, Jean-Fabien Spitz insiste no papel desempenhado pela distinção entre a associação e a constituição do governo na teoria contratualista de Pufendorf: "L'analyse proposée par Pufendorf repose sur l’idée que la société civile n’est complete que si elle réalise deux liens distincts l'un de l'autre: l'association ou union d'une part, et la soumission ou sujétion d'autre part” (SPITZ, 1987, p. 85). Aqui, também não há consenso entre os comentadores, Fiammetta Palladini defende que o núcleo fundamental da doutrina de Hobbes é conservado, pois, para a fundação do Estado, só é decisivo o segundo pacto, através do qual a multidão é unificada num corpo que age como se fosse uma só pessoa (PALLADINI, 1990, p. 34-39). Embora apresente uma leitura criteriosa e fina, estou inclinado a defender a necessidade dos dois pactos e, por isso, atribuir razão aos argumentos de Spitz e recusar as teses de Palladini. A teoria do duplo contrato e a distinção entre associação e sujeição permite, a meu ver, manter uma relativa autonomia jurídica do povo que não havia no dispositivo contratual de Hobbes. A ausência provisória do soberano não conduz ao desaparecimento completo da sociedade civil. A mesma teoria permite, além disso, fundar sobre uma convenção a relação jurídica entre o soberano e seus súditos. Em suma, a teoria do duplo contrato reflete um desacordo mais importante, qual seja, a definição de direito natural. Além disso, Victor Goldschmidt ressalta a importância do papel desempenhado pelo termo lei fundamental no pensamento moderno e sua longa tradição: "On sait que cette expression remonte au XVIe siècle, et qu'elle joue un rôle éminent dans les luttes politiques en France, en Anglaterre et dans les colonies anglaises du Nouveau Monde. On notera ici deux points. L'idée de loi fondamentale, comme l'a montré Jellinek, se joint à celle, plus ancienne, d'un contrat constitutionnel entre le roi et le peuple (c'est cette conception contractuelle qui prévaut chez Pufendorf et Burlamaqui). D'autre part, Hobbes constate, en 1651: 'Je n'ai jamais pu voir chez un auteur ce que signifie loi fondamantale'. Lui-même considère comme 'fondamentale dans chaque cite, la loi dont la suppression dissoudrait la cité. Or l'unique loi fondamentale est celle qui enjoit aux citoyens d'obéir à la personne de la cite, c'est-à-dire à celui qui détient le pouvoir suprême. Car, cette loi supprimée, la cite n'est plus; si elle subsite, la cité elle aussi demeure'. Autrement dit, la loi fondamentale est le pacte d'union” (GOLDSCHMIDT, 1983, p. 667-668). 
argumentos de Hobbes, o jurista alemão explica a formação do Estado por dois pactos bem diferentes entre si: a primeira convenção é o desejo dos indivíduos pela formação de uma mesma associação civil, é um pacto de união que une os cidadãos e impõe obrigações mútuas. A segunda convenção comporta dois aspectos, a escolha do soberano mediante um acordo contratual dos associados e o compromisso de obediência irrestrita, e a troca de promessas mútuas entre o soberano e seus súditos - o primeiro promete a proteção de todos e agir em busca do bem comum, os segundos prometem obediência (PUFENDORF, 1998b, VII, II, §§7-8). É um pacto de submissão. Entre eles, porém, há um decreto dos associados para decidir a forma de governo. Para Pufendorf, ambos os movimentos de constituição do corpo político são absolutamente necessários.

O primeiro acordo tem origem entre homens livres, independentes, responsáveis e racionais na insegurança do estado de natureza: todos aceitam formar uma associação. Eles decidem que a forma de administrar a segurança coletiva e individual se articula mediante o acordo mútuo e reconhecimento da liderança capaz de ditar as normas a seguir. Este acordo é denominado coetus, união simples entre os homens para assegurar a sobrevivência. Em essência, o pacto de associação requer "o consentimento, expresso ou tácito, de todos os particulares.” Quem não aceita participar desta aliança permanece fora da sociedade e conserva sua liberdade natural, está entregue a própria sorte e deve arcar com o ônus da providência dos meios materiais de sua própria conservação. Os associados que recorrem à aliança estão, por isso, desobrigados do socorro aos não-associados. A finalidade do pacto é ao mesmo tempo superar a condição de insegurança natural e infrapolítica dos homens, garantido o auxílio mútuo, e iniciar "o começo e o esboço de um Estado" (GOYARD-FABRE, 1994, p. 171). Mas nesse estágio não há ainda sujeição, a pluralidade das vontades individuais não constitui ainda o poder de coação e o governo capaz de aplicar leis e dominar os súditos. Por essa razão, ela permanece frágil e precária e qualquer um pode na ausência de coação jurídica violar os compromissos. O direito natural - cuja análise da promessa estabeleceu que ela é a condição de validade e origem dos compromissos - corre o risco de ser desrespeitado ou simplesmente ignorado pelos associados. Tal união estaria sempre ameaçada e não poderia por si mesma durar muito tempo. Como no estado de natureza, a associação é ainda imperfeita: sem leis, sem poder executivo, sem jurisdição.

O pactum unionis assim descrito é necessário, mas não é suficiente para engendrar a sociedade civil autêntica e durável. Um segundo compromisso deve permitir por um decreto (decretum) fixar e regrar "a forma de governo". É um acordo determinado pela escolha da maioria: “uma decisão sobre qual forma de governo se deve estabelecer" (PUFENDORF, 1997, II, VI, §8). Assim, estão desenhados os contornos da regra majoritária que 
Pufendorf, antes de Locke, vê claramente como um dos suportes mais sólidos do governo de Estado (GOYARD-FABRE, 1994, p. 172).

Mas ainda não atingimos o objetivo proposto, pois o primeiro acordo recíproco deve ser completado com um outro, o contrato de governo, que estrutura a forma da soberania a partir da submissão dos indivíduos à autoridade. Só com este passo definitivo dos associados, portanto, é possível se chegar a ordenar politicamente a sociedade do contrato de união, dando lugar a uma organização política formada pelo soberano e cidadãos: um "Estado perfeito e regular [perfecta \& regularis civitas]” (PUFENDORF, 1997, II, VI, §9). Esta segunda aliança implica obrigações recíprocas entre todos os membros associados e as instituições: os cidadãos fazem juras de obediência irrestrita à autoridade, que deve observar as leis inerentes a sua condição de governante. Por sua vez o governante se compromete a resguardar o Estado e suas instituições mediante o exercício da suprema autoridade, o que significa preservar a segurança dos cidadãos e garantir o progresso social e econômico de todos (BUCKLE, 1991, p. 108-124). É um contrato semelhante ao que foi proposto um século antes pelos Monarcômacos, ${ }^{14}$ cujo compromisso recíproco dos governantes e governados estabelece um vínculo relacional permanente; mais exatamente, é um contrato fundado sob as bases da troca entre a autoridade soberana e os súditos, também conhecido como contrato de submissão e sujeição. É somente a partir do encontro das vontades dos associados que o Estado pode ser considerado tecnicamente formado e efetivamente existir. Assim, quando é posto em funcionamento o acordo o Estado é constituído de modo completo e regular. O Estado formado a partir da união das vontades permite, portanto, que consideremos o poder político como a sociedade dos homens com nomes próprios - que implica a individualização de cada sujeito -, parentescos, posses e famílias. Mas como estrutura hierárquica, diferenciadora e unitária da vontade e do poder, o corpo político é acima de tudo independente do governante e dos indivíduos que o iniciam e chegam a constituí-lo. É um "ser moral composto" que não se reduz aos elementos simples de sua composição (PUFENDORF, 1998a, I, I, §13).

\footnotetext{
${ }^{14}$ Robert Derathé lembra que a teoria do pacto de submissão remonta à concepção da monarquia eletiva e suas origens datam da Idade Média. Mas foi somente a partir do século XVI que a teoria se tornou popular e se viu vinculada a maior parte das controvérsias e polêmicas relativas aos poderes e obrigações do monarca diante de seus súditos. Ela é amplamente formulada por Junius Brutus - pseudônimo provavelmente inspirado em Marcus Junius Brutus, o assassino de César, citado no texto quando da questão do tiranicídio - em seu Vindiciae contra Tyrannos de 1579 (DERATHÉ, 1970, p. 208). A obra é frequentemente atribuída aos huguenotes Hubert Languet e Philippe Duplessis Mornay. Este último teria trabalhado e apresentado o texto definitivo a partir da primeira versão de Languet (TERREL, 2001, p. 73-96).
} 
Operando-se dessa maneira, Pufendorf pensa ter conseguido conciliar a liberdade individual com as necessidades da vida social, pois o Estado estaria apto a cumprir a paz em seus quatro aspectos: segurança vital (ser membro e estar capacitado para administrar a justiça), segurança para promover a doutrina cristã, segurança material para viver com dignidade segundo políticas econômicas que proporcionem o bem-estar de todos, e segurança para distribuir com justiça as honras governamentais. Desse modo, podem-se superar definitivamente os problemas derivados da passagem do estado de natureza à sociedade, superar obstáculos como a ingratidão, a inimizade e a falta de cooperação social (PUFENDORF, 1998b, VIII, IV). Em termos de interesse pessoal, talvez, pode não valer a pena realizar algum ato cooperativo que contribua para a provisão de algum bem coletivo. Mas se os indivíduos não raciocinam em termos de interesse pessoal apenas e levam em conta seu interesse pelos outros, eles podem encontrar a cooperação racional. Para Pufendorf, o corpo político cria efetivamente o refúgio seguro dos cidadãos sociáveis e cooperativos. Só ele é capaz de garantir a paz social e realizar assim plenamente a condição humana em geral, a de ser um sujeito de relação com vínculos sociais permanentes. Por fim, o Estado não tem legitimidade para contrariar os direitos naturais e o direito positivo ou construído deve realizar os princípios ali contidos. ${ }^{15}$ Para Pufendorf, o homem tem uma dignidade inalienável, na medida em que, pela sua própria natureza, é sujeito de direitos.

\footnotetext{
15 Embora sustente que o direito positivo depende do direito natural, e rejeite a tese hobbesiana de que o Estado não pode causar dano a um cidadão, Pufendorf não oferece uma resposta muito animadora aos defensores do direito de resistência quando os danos provocados pelos governantes são sérios. Se num primeiro momento desobriga os cidadãos da obediência cega a uma ordem superior "repugnante ao comando de Deus", num segundo momento, porém, defende a fuga e a busca de proteção em território estrangeiro como alternativa mais aceitável. Mas, "se a fuga não for possível, um homem deve antes ser morto que matar, não tanto pela pessoa do príncipe quanto por toda a comunidade, que geralmente é ameaçada com grandes tumultos em tais circunstâncias” [“Quin \& si fugae via non datur, moriendum potius, quam occidendum est, non tam propeter ipsius principis personam, quam propter totam remp., quae tali occasione gravibus fere turbis solet involvi”] (PUFENDORF, 1998b, VII, VIII, §5). Prevalece nestes casos limites a razão de estado (LARRÈRE, 1992, p. 33-36; DUFOUR, 1996, p. 107-138). Ainda assim, Alfred Dufour insiste no traço mais importante de Pufendorf, no ecletismo de seu pensamento, para se compreender a política do autor. É à luz desse ecletismo que devemos ler o autor saxão (DUFOUR, 1987, p. 104).
} 


\section{REFERÊNCIAS}

ALTHUSIUS, J. Política methodice digesta. Cambridge: Harvard University Press, 1932.

BEHME, T. Samuel pufendorf: naturrecht und staat. Göttingen: Vandenhoeck \& Ruprecht, 1995.

BOBBIO, N. Thomas Hobbes. Tradução de Carlos Nelson Coutinho. Rio de Janeiro: Campus, 1991.

BRUFAU PRATS, J. La actitud metodica de pufendorf y la configuracion de la Disciplina Juris Naturalis. Madrid: IEP, 1968.

BUCKLE, S. Natural law and the theory of property: grotius to hume. Oxford: Clarendon Press, 1991.

CARR, C. L.; SEIDLER, M. J. The political writings of samuel pufendorf. New YorkOxford: Oxford University Press, 1994.

DENZER, H. Moralphilosophie und naturrecht bei samuel pufendorf: Eine geistes und wissenschaftsgeschichtliche untersuchung zur geburt des naturrechts aus der praktischen philosophie. Müchen: C. H. Beck, 1972.

DERATHÉ, R. Jean-Jacques Rousseau et la science politique de son temps. $2^{\mathrm{e}}$ éd. Paris: Vrin, 1970.

DUFOUR, A. Jusnaturalisme et conscience historique dans la pensée politique de Pufendorf. Cahiers de Philosophie Politique et Juridique, Paris, n. 11, p. 103-125, 1987.

. Federalisme et raison d'etat dans la pensée politique pufendorfienne. In: FIORILLO,

V. (Org.). Samuel Pufendorf filosofo del diritto e della politica. Atti del Convegno Internazionale. Milano, 11-12 novembre 1994. Napoli: La Città del Sole, 1996, p. 107-138.

GOLDSCHMIDT, V. Anthropologie et politique: les principes du système de Rousseau. $2^{\mathrm{e}}$ éd. Paris: Vrin, 1983.

GOYARD-FABRE, S. Pufendorf et le droit naturel. Paris: PUF, 1994.

O que é democracia? São Paulo: Martins Fontes, 2003.

Filosofia crítica e razão jurídica. São Paulo: Martins Fontes, 2007.

GROTIUS, H. De iure belli ac pacis libri tres, in Quibus Ius Naturae Et Gentium, Item Juris Publici Parecipua Explicantur Cum Annotatis Auctoris. Edited by P. C. Molhuysen. Lugduni: A. W. Sijthoff, 1919. 
HAAKONSSEN, K. Natural law and moral philosophy: from grotius to the scottish enlightenment. Cambridge: Cambridge University Press, 1996.

HAAS, J. Die reichstheorie in pufendorfs "Severinus de Monzambano". Berlin: Duncker \& Humblot, 2006.

HAGGENMACHER, P. Grotius et la doctrine de la guerre juste. Paris: PUF, 1983.

HOBBES, T. Leviathan. Cambridge: Cambridge University Press, 1996.

HOCHSTRASSER, T. J. Natural law theories in the early enlightenment. Cambridge: Cambridge University Press, 2000.

HUNTER, I. Rival Enlightenments: civil and metaphysical philosophy in early modern germany. Cambridge: Cambridge University Press, 2001.

LARRÈRE, C. L'invention de l'économie au XVIIIe siècle: du droit naturel à la physiocratie. Paris: PUF, 1992.

LAURENT, P. Pufendorf et la loi naturelle. Paris: Vrin, 1982.

LOCKE, J. Two treatises of government. Cambridge: Cambridge University Press, 1988.

OLIVEIRA, M. A. Ética e sociabilidade. 2. ed. São Paulo: Loyola, 1996.

PALLADINI, F. Discussioni seicentesche su Samuel Pufendorf. Scritti latini: 16631700. Bologna: Società Editrice Il Mulino, 1978.

Samuel Pufendorf discepolo di Hobbes: per uma reinterpretazione del giusnaturalismo moderno. Bologna: Società Editrice Il Mulino, 1990.

PUFENDORF, Samuel. Gesammelte werke. Band 2: de officio. herausgegeben von gerald hartung. Berlin: Akademie Verlag, 1997.

Gesammelte werke. Band 4.1: de jure naturae et gentium (Liber primus Liber quartus). Herausgegeben von Frank Böhling. Berlin: Akademie Verlag, 1998a.

Gesammelte werke. Band 4.2: de jure naturae et gentium (Liber quintus Liber octavus). Herausgegeben von Frank Böhling. Berlin: Akademie Verlag, 1998b.

SCATTOLA, M. Ordem e imperium: das políticas aristotélicas do começo do século XVII ao direito natural de Pufendorf. In: DUSO, G. (Org.). O poder: história da filosofia política moderna. Tradução de Andrea Ciacchi e Giuseppe Tosi. Petrópolis: Vozes, 2005. p. 94-110.

SCHINO, A. Il pensiero politico di pufendorf. Roma: Laterza, 1995. 
SCHMIDT-BIGGEMANN, W. Samuel von Pufendorf - Filosofia do Estado e do direito entre o barroco e o Iluminismo. In: KREIMENDAHL, L. (Org.). Filósofos do século XVII. Tradução de Benno. Dischinger. São Leopoldo: Ed. Unisinos, 2003. p. 148-174.

SEVÈ, R. Leibniz et l'école moderne du droit naturel. Paris: PUF, 1989.

SPITZ, J-F. La theorie du double contrat chez Grotius et chez Pufendorf. Cahiers de Philosophie Politique et Juridique, n. 11, p. 75-99, 1987.

TERREL, J. Les théories du pacte social: droit naturel, souveraineté et contrat de Bodin à Rousseau. Paris: Seuil, 2001.

TUCK, R. Natural rights theories: their origin and development. Cambridge: Cambridge University Press, 1979.

. Introduction. In: HOBBES, T. Leviathan. Cambridge: Cambridge University Press, 1996. p. 9-92.

The rights of war and peace: political thought and the international order from Grotius to Kant. Oxford: Oxford University Press, 1999.

VILLEY, M. A formação do pensamento jurídico moderno. Tradução de Cláudia Berliner. São Paulo: Martins Fontes, 2005.

WELZEL, Hans. La dottrina giusnaturalistica di Samuel Pufendorf: un contributto alla storia delle idee dei secoli XVII e XVIII. Tradução de Vanda Fiorillo. Torino: Giappichelli, 1993.

WOLF, E. Grotius, Pufendorf, Thomasius: Drei Kapitel der gestaltgeschichte der rechtswissenschaft. Tübingen: J. C. B. Mohr, 1927.

ZURBUCHEN, S. Naturrecht und natürliche Religion: zur Geschischte des toleranzbegriffs von Samuel Pufendorf bis Jean-Jacques Rousseau. Würzburg: Königshausen \& Neumann, 1991. 